\section{Selection of Medical Students}

SIR,-Dr. Andrew Smith's musings in "Personal View" (20 January, p. 176), though delightful to read, do scant justice to the problems faced by those of us who have to select $n$ medical students from $x \times n$ applicants, where the real value of $x$ (i.e., allowing for multiple applications) is probably never less than two. It is simply not true that " nobody questions" entrance requirements, and Dr. Smith really should know better than to generalize from a (very atypical) sample of two fellow-students whose basis of success seems evident through hindsight.

Dr. Smith is impressed by the Cambridge research. So am I. But just how relevant is it to the selection process for admission to medicine? Every admissions committee is interested in better methods of predicting student performance, if these are valid, reliable, and feasible, and many of us who are involved in the selection process would like to set up experiments to prove or disprove our ideas. It would indeed be fine if we could test Dr. Smith's view that advanced school qualifications in science are not a prerequisite for modern medical education-but what would happen to the failures? Would boys and girls with a school arts or "nonpure" scientific education who could not master first M.B. science really believe that they would have done no better with a pure science course at school ?

Of course there is an occasional bright youngster who makes a late change in choice of career and presents the university medical selectors with good grades in arts subjects. In Aberdeen the door is not closed to such people, but we have had sufficient experience to know that it is unfair to both students and teachers to open wide that door. Young lives and aspirations are too precious to risk a policy that could severely damage even a few of them.

We selectors, I assure Dr. Smith, will continue to scrutinize, review, and modify our procedures in the hope that better understanding of what produces good doctors will lead to firmer predictive criteria for choosing who shall have the privilege of medical education. But I rather think that we shall always want a balance between "convergers" and "divergers." - I am, etc.,

I. M. RICHARDSON.

Admissions Committee of the Faculty University of Aberdeen.

\section{More Cases of Scabies}

SIR,-The epidemic of scabies reported last year (18 March 1967, p. 669) is gathering momentum. The incidence of scabies in new outpatients in 1967 at St. John's Hospital for Diseases of the Skin, London, was 2.9\% (490 of 16,661 new patients) according to the records department.

This represents a further rise of $0.5 \%$ on the previous year, so that over the last three years the incidence has trebled. If this rate of increase continues public facilities for therapy, such as local authority cleansing centres, may well prove necessary to cope with the problem, particularly for patients in poor housing and those who cannot comprehend the instructions for therapy. In Shrop- shire in 1967 the incidence of scabies in new dermatological outpatients was $2 \%$, indicating that the problem is of the same order in a rural population as in an urban one. Figures for previous years are not available, so the epidemic trend cannot be confirmed.

It is doubtful whether education or earlier consultation is sufficient to limit spread of the disease. A more vigorous concern for treating symptomless contacts may be effective, and perhaps our efforts should be directed to this end rather than simply to treating the patient. - We are, etc.

$$
\begin{aligned}
& \text { Alan B. ShraNK. } \\
& \text { Royal Salop Infirmary. } \\
& \text { Shrewsbury. SUZANNE L. ALEXA } \\
& \text { St. John's Hospital for } \\
& \text { Diseases of the Skin, } \\
& \text { London W.C.2. }
\end{aligned}
$$

\section{Restrictions on Doctor in South Africa}

SIR,-In various letters and comments in the B.M.F. on the recent banning order served on Dr. R. Hoffenberg, of Cape Town University, half-truths and false impressions have been created, the most recent by Dr. $S$. Shapiro (16 December, p. 684). His final paragraph exposes him to severe criticism and creates an entirely wrong impression in the minds of thousands of colleagues who are not aware of the exact conditions existing in South Africa. In fact it reeks of the villainous anti-South-African propaganda poured out by an inimical lay press.

A:low me to put a few of his statements in the right perspective. "The major consideration that prompted my resignation was political." As a scientist and a medical man in South Africa there is hardly scope for politics. Medicine and scientific research extend over all sections of the population irrespective of colour, creed, race, or personal political ideas. It is true that South Africa has a relative shortage of doctors, but even so the standard of practice of medicine and medical research in South Africa compares favourably with the best in the world. There are ample facilities and a vast scope as well as material for research, and, even though the country has not as yet the vast resources to finance unrestricted research, any deserving project is amply provided for by funds from both the Government and provincial administrations as well as from the private sector of the population and commerce and industry.

As regards Dr. Shapiro's statement about "academic life in a politically suppressive atmosphere," nothing can be further from the truth. It exposes an absolute lack of knowledge of precise conditions in South Africa.-I am, etc.

$$
\begin{gathered}
\text { Kroonstad, O.F.S., } \\
\text { South Africa. }
\end{gathered} \quad \text { G. F. C. TROSkIR. }
$$

\section{Difiuse Fibrosing Alveolitis}

Sir,-Professor Scadding, when he introduced this term,' interpreted it as indicating " that histopathological changes of a certain broad type are present in the lung"; he also stressed the advantages which stemmed from "the freedom of this term from aetiological implications. ..." Subsequently, in reply to Professor Gough, ' he defended the omission of the prefix "idiopathic" for conditions in which the aetiology was unknown, on the grounds of it being very cumbersome. Your leader writer (27 January, p. 199) is of the same opinion. However, he would seem to be ill-advised to exclude some disorders (for example, beryllium disease) which fulfil the criteria that have been suggested. This is illogical and strengthens the case of Drs. J. M. E. Seal and J. C. Wagner, who would abandon the term altogether (25 November 1967 , p. 485).

It is not my purpose to argue what term should be used, but its definition, once established on a basis of histopathology, should surely be adhered to regardless of aetiology and not altered unless it is found to be inadequate. On this basis diffuse fibrosing alveolitis may have an allergic origin, be due to inhalation of certain inorganic dusts, or arise in ways which at present should be described as idiopathic.-I am, etc.,

\section{Medical Research Council
Pneumoconiosis Research Unit. \\ Llandough Hospital.
Penarth, Glam.} J. E. Cotes.

REPBRENCBS

Scadding, J. G., Brit, med. 7., 1964, 2, 686.

Gough, J., ibid., 1964, 2, 818.

\section{Cranial Bruits}

SIR,-Dr. H. Gareeboo (3 February, p. 294) draws attention to bruits over areas of the skull in three patients following acute blood loss. He states that severe anaemia in adults seems to be a fairly common cause of cranial bruit in general medical wards. In this centre we too recognize that cranial bruits occur in anaemia and can disappear when the haemoglobin is raised to normal. The patient who presents with symptoms of an intracranial vascular malformation and a bruit but who is also anaemic poses a problem in diagnosis, and arteriography is often necessary to exclude a malformation. The following case reports illustrate some of the problems.

Cass 1.-A woman aged 23 was admitted on 15 December 1966 under the care of Dr. G. S. Graveson with a three-week history of frontal headaches, the first accompanied for two hours by nausea and retching. The aches became localized during the following days over the left eye and occiput, throbbing in time with her pulse, and she noticed a hissing noise in the left car. She described occasional headaches for several years, and for three years she had taken Orthonovin (norethisterone, mestranol) as a contraceptive. The present headaches started in the middle of a course. There was no family history of migraine. General examination revealed no abnolity apart from pale mucous membranes and a blood pressure of $140 / 90 \mathrm{~mm}$. Hg. There were no cardiac murmurs. A systolic bruit was heard over the right eye, and was accentuated by left and reduced by right carotid compression. Botb plantar reflexes were extensor and the deep reflexes slightly increased on the right. Carotid compression was attempted but had to be discontinued after two minutes on the left side and after four minutes on the right owing to a feeling of faintness.

Relevant haematology was: Hb $6 \mathrm{~g} .1100 \mathrm{ml}$, M.C.H.C. $28 \%$, iron-deficiency changes on the film, and fasting morning serum iron $81 \mu \mathrm{g} . /$ $100 \mathrm{ml}$. E.E.G. and skull $x$-rays were normal. The anaemia was corrected by transfusion of four pints of blond, which raised the haemoglobin to $11.3 \mathrm{~g} .1100 \mathrm{ml}$. ; the bruit disappeared at once and the headache had gone the following day. The abnormal neurological signs also disappeared, so no angiography was performed. The anaemia 
was thought to be due to menstrual loss, and the patient has remained well.

Case 2.-A woman aged 45 was admitted under the care of Dr. L. S. Illis on 3 January 1968 with a 24-year history of attacks of right occipital headache on the first or fifth day of menstruation. For the first 12 hours of each headache she also noticed vomiting, photophobia, and neck stiffness. She had not had cyclical vomiting as a child, but one sister had migraine. She had heard no bruit, but had noticed the beadache worsened with alcohol; she was not taking an oral contraceptive. General examination revealed no abnormality apart from a blood pressure of $180 / 90 \mathrm{~mm}$. Hg; there were no cardiac murmurs. Bilateral carotid and orbital bruits were heard; the carotid bruits were abolished by carotid compression, but both orbital bruits remained. At one time a soft right occipital bruit was heard and did not disappear with carotid compression. The remainder of the neurological examination was normal.

Relevant haematology was: $\mathrm{Hb} 9.2 \mathrm{~g} . / 100 \mathrm{ml}$., M.C.H.C. $29 \%$, irnn-deficiency changes on the film. E.E.G. showed some 14-16 c.p.s. activity symmetrically mixed with the alpha frequencies. Bilateral carotid and catheter right vertebral angiography were normal, and the day following this the right carotid and occipital bruits had disappeared. Six days after angiography both carotid bruits had disappeared and the orbital bruits were much fainter. The patient was discharged with $\mathrm{Hb} 8.7 \mathrm{~g} . / 100 \mathrm{ml}$.

The anaemia in these patients was of less sudden onset than that in Dr. Gareeboo's patients. In Case 1 the regression of symptoms and signs after transfusion with subsequent good progress justified the decision not to undertake angiography. Case 2 demonstrated an alteration of bruits after angiography, although at the same time the haemoglobin fell (perhaps within the limits of experimental error). So bruits are rather labile signs, and we hope to study further their significance in neurological disorders. The differentiation of tinnitus in anaemia from a bruit heard by the patient should not normally be difficult. Tinnitus may occur in postural hypotension, and its nature will be known to many by personal experience; some patients with cranial bruits can describe exactly the same noise as that heard by the observer with his stethoscope, and can time it with the pulse.-I am, etc.,

Christopher Gardner-ThORPE.

Wessex Neurological Centre,

Tampton General Hospital,

Southampton, Hants.

SIR,-Dr. H. Gareeboo does well to draw attention to the presence of cranial bruits in severe anaemia (3 February, p. 294), a finding not mentioned in standard textbooks, although, I believe, familiar to most neurologists. He is not, however, the first to publish this finding, which was discussed in the excellent review by Allen and Mustian.' -I am, etc., Department of Medicine,
University of Aberdeen.

Allan W. Downie.

\section{REFERENCB}

- Allen, N., and Mustian, V., Medicine (Baltimore), 1962, 41, 227

\section{Vaccination for Measles}

SIR,-Money, we know, is short for the Health Service, yet a programme of general immunization costing $\hat{x} 1 \mathrm{~m}$. is to be started in the spring.

I have not seen a complication of measles for at least the last four epidemics and I do not prescribe routine antibiotics. A child who contracts measles is ill for a few days and is protected for life. An injection of live vaccine may protect during childhood with a possible reaction for a day or two, leaving the possibility of measles infection in adolescence or later-a risk to be run, and an unpleasant one.

What does the individual gain? Can we afford this indefinite advantage at present ? -I am, etc.

Stourbridge, Worcs. MARY J. BARTLETT.

\section{General-practitioner Obstetrics}

SIR,-One reads so much that is critical of general-practitioner maternity units that some attempt should be made to correct the perspective with regard to this valuable part of the obstetric services in Britain.

Some of these criticisms are made by medical men who are not obstetricians and who cannot have a first-hand knowledge of this subject or of those qualities in generalpractitioner maternity units which are not expressed in their statistics. As an example, the patients who attend large specialist units often say that they see a different doctor at each visit. In this way the progress of an abnormal condition is less satisfactorily observed and contradictory lines of action may be followed by successive doctors. Continuity of care in the case of the general practitioner is an important feature and is the kind of quality which is not measured statistically.

The interpretation of the statistics is open to challenge. Repeatedly reasons are produced showing why figures which appear favourable to domiciliary and general-practitioner maternity unit confinements should be regarded as unfavourable, whi'e the opposite procedure is applied to hospital figures.

Butler"and Bonham have suggested that general-practitioner maternity units should be considered as "collective domiciliary obstetrics under good conditions rather than as an obstetric hospital." Hobbs and Acheson state $^{2}$ " that the advantages they offer compared with domiciliary practice are that a trained midwife is always immediately available, they have labour rooms, and they are more accessible to the ambulance and flying squad services." The general trend in fac nowadays is to credit the general-practitioner obstetrician with the ability to supervise the normal delivery of a second or third baby, provided the previous delivery was normal, and perhaps in extreme cases to perform outlet forceps.

In reality the general-practitioner accomplishes far more than this, and many are accustomed to dealing with most obstetric problems other than caesarean section. In an obstetric hospital the consultant and registras usually both live out and do not expect to be called at night for a forceps delivery. The houseman is usually left to do the job. A general-practitioner obstetrician, however, with years of experience added to his knowledge as a houseman, is no longer considered capable of this task.

It has been stated ${ }^{2}$ that practices with access to general-practitioner maternity units have a significantly higher perinatal mortality than do those without access. In our local general-prac titioner maternity unit the perinatal mortality rate for 1967 was 6.5 and for 19665.8 per 1,000 .
(18 per 1,000 in South Oxfordshire in 1965.) (see Table I).

TABLE I.-Statistics Relating to Local Generalpractizioner Maternity Units

\begin{tabular}{|c|c|c|c|c|}
\hline & & & 1966 & 1967 \\
\hline $\begin{array}{c}\text { Live births: } \\
\text { Primiparae } \\
\text { Multiparae }\end{array}$ & $\because$. & $\because$ & 512 & $\begin{array}{l}252 \\
209\end{array}$ \\
\hline $\begin{array}{l}\text { Still births } \\
\text { Neonatal deaths } \\
\text { Transfer to specia } \\
\text { Primiparae } \\
\text { Multiparae }\end{array}$ & 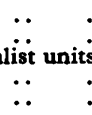 & \begin{tabular}{c|}
$\because$ \\
$\ddot{t s}$ \\
$\ldots$ \\
..
\end{tabular} & \} 36 & $\begin{array}{l}1 \\
\text { Nil } \\
19 \\
10\end{array}$ \\
\hline $\begin{array}{l}\text { Flying squad: } \\
\text { Mothers } \\
\text { Babies } \\
\text { Forceps deliveries } \\
\text { Breech } \\
\text { Twins \#. }\end{array}$ & $\begin{array}{l}\because \\
\ddot{x} \\
\because\end{array}$ & $\begin{array}{l}\ddot{z} \\
\ddot{z} \\
\ddot{.}\end{array}$ & $\begin{array}{c}1 \\
16 \\
16 \\
6 \\
2 \text { sets }\end{array}$ & $\begin{array}{c}3 \\
1 \\
16 \\
3 \\
2 \text { sets }\end{array}$ \\
\hline
\end{tabular}

maternity units.

In the figure of 29 transferred to specialist units there were two perinatal deaths, both of which have been included in calculating the perinatal mortality rate for 1967 . In one case the mother arrived at the general-practitioner maternity unit with the cord prolapsed and not pulsating ; in the other case it was still pulsating on arrival at the specialist unit, but the foetus died before it could be delivered.

The figures relating to place of confinement are very variable and can even vary from one part of a group practice to another. I reviewed 100 deliveries in my own practice, which compare with the figures in the Perinatal Mortality Survey as follows:

\begin{tabular}{|c|c|c|}
\hline $\begin{array}{c}\text { Place of } \\
\text { Confinement }\end{array}$ & $\begin{array}{l}\text { Perinatal } \\
\text { M.S. }\end{array}$ & $\begin{array}{c}\text { Own } \\
\text { Practice }\end{array}$ \\
\hline $\begin{array}{l}\text { Home } \\
\text { G.P.M.U. } \\
\text { Specialist unit } \\
\text { Others }\end{array}$ & $\begin{array}{l}36 \% \\
12 \% \\
49 \% \\
3 \%\end{array}$ & $\begin{array}{l}34 \% \\
47 \% \\
19 \%\end{array}$ \\
\hline & $100 \%$ & $100 \%$ \\
\hline
\end{tabular}

According to Hobbs and Acheson, generalpractitioner units accounted for less than $20 \%$ of deliveries in 1962 in the Oxford area. The specialist unit deliveries of my patients consisted of lower segment caesarean section 6, forceps 2 , breech 2, Rh sensitization 3 , and normal deliveries 6-a total of 19.

The six caesarean sections were due to one case each of unstable lie, elderly primipara with nephrectomy during pregnancy, elderly primipara with breech, previous lower segment caesarean section and disproportion, third lower segment caesarean section, and prolapsed cord.

At the maternity unit there were four forceps deliveries out of 47 deliveries-two for deep transverse arrest and two for delay in the second stage of labour. A survey of the nert $100 \mathrm{de}$ liveries was remarkably similar: 37 were confined at home, 47 at the unit, and 16 at specialist units.

Mothers living at the other end of this group practice (whose figures are not included here) are nearer to Oxford and that much further from our general-practitioner maternity unit. A higher proportion of these mothers are booked at the specialist units in Oxford.

I certainly do not accept that mothers have suffered through being further away from a specialist unit, or from being confined at our general-practitioner maternity unit, which is halfway between Oxford and Reading and about 12 miles from either centre.

It is for the general practitioner to decide whether the mother should be booked at a specialist unit, and in my experience patients accept the decision when the reasons are explained to them. This selection of cases is a highly important part of general-practitioner obstetrics in order that the relatively 